\title{
Facilitating Teaching and Learning with Made to Measure Fashion Design and Creation MOOC Courses
}

\author{
Tanya Dove
}

\begin{abstract}
Massive Online Open Courses (MOOC) provides a flexible and engaging learning environment. $\mathrm{A}$ MOOC in Apparel Technology facilitates a comprehensive e-Learning platform, with a variety of instructional videos and technical resources, which will foster a technical foundation in pattern cutting and sewing for learners. Apparel technology is a core skill for fashion design students; however, universities only address a limited range of construction techniques within their curriculum. Students work towards model size apparel for their graduate fashion shows, which limit the learner's knowledge in developing apparel for different body shapes. A MOOC in Apparel Technology would facilitate learners with the skills and knowledge to develop apparel for different sizes and figure shapes, with fit assessment and problem-based forums on fit solutions.

With many retailers now providing a global platform for the sales of clothing, the sizing of women's clothing is an area of concern in the fashion industry, 'one size does not fit all'. The inconsistencies in garment sizing can contribute to the dissatisfaction of garment fit, leaving women unable to find, or know, what size fits their body shape. MOOC incorporates an innovative design and eLearning platform, in a less structured approach, which harnesses learning in an interactive setting, with online interactions prompting learners to collaborate, share ideas and examples, in a less structured environment.
\end{abstract}

Index Terms-MOOC, e-learning, apparel technology, pattern cutting, women's figure shapes.

\section{INTRODUCTION}

Global retail sales were projected to amount to around 30 trillion U.S. dollars by 2023, up from approximately 23 trillion U.S. dollars in 2017 [1], with the market's largest segment being Women's Apparel, with a market volume of US $\$ 994,321 \mathrm{~m}$ in 2020 [2]. The online sales of clothing, accessories and footwear in the UK was GBP 16.2 billion in 2017 , with an estimated growth rate of $17.2 \%$ for the following years; however, over $60 \%$ of fashion items are returned by customers [3]. This significantly high figure of returns is considered as a big problem in the fashion industry, and retailers are continuously seeking for a solution to this. One of the major reasons behind this problem is the poor fit (43\% of returns), or the size label of clothing that drives customers to return the items they purchase, as shown by Mintel.

A study by Gill [4] in innovation in garment sizing, confirms the greatest recent contribution to the sizing and fitting of clothing has come from advances in computer technology. Body scanning has become integral to the development and evolution of the fashion industry in the sizing of clothing, with National databases of body measurements offering refined data sets, which can be used with Computer Aided Design (CAD) and Computer Aided Management (CAM) systems, to enable quicker and more accurate development of patterns and virtual try-on. Gribbin [5] study showed that these technology systems could all contribute to the development of new and effective ways to provide an improved fit of clothing. However, body scan technology also has inaccuracies in locating specific landmarks on a body. Kim [6] shows that body scanner output depends on the clothing worn by the subject. Bougourd [7] stated that it would be expected that many body landmarks would be extremely difficult to locate from the 3D body scan image. The measurement of the waist has been a perennial problem in clothing. To obtain the accurate waist measurement from a 3D scan would require the subject to have a defined waist position. For larger subjects where body mass has accumulated at the waist level, this could be problematic for the 3D scanner to locate the exact waist height position, and consequently the waist girth.

However, the technological advancements in body scanning and virtual fitting rooms are not addressing the fundamental problem of the sizing of clothing, they are looking at the finished production, or body avatar, and fitting mass-produced clothing onto this form. Gill [4] states that although automated pattern development directly from body measurement has been steadily developing, the fundamental constriction, affecting the more widespread application of automated pattern construction, is in the establishment of more direct relationships between body and garment, within the context of learning about pattern construction. To date, no such methods have the ability to provide direct translation of body scans in to accurate pattern shapes. Schofield [8] confirms disconnects between anthropometric measures and size charts also contribute to discrepancies between the garments and the consumers that they are intended to fit.

\section{FASHION DESIGN EDUCATION}

As stated by Hodges [9] higher education programmes that prepare students for careers in fashion have much to gain by keeping pace with the industry's changing needs. Alongside current industry dynamics, a global economic downturn and academic programme restructuring continue to create the need for a proactive stance in recruitment and retention on the part of faculty and administrators. Romeo [10] sampled 240 apparel industry professionals, in an online industry skills 
survey. Patternmaking is a current required course for technical design students, for most Global and US apparel programmes; however, the feedback from the industry indicates that few recent college graduates possess strong patternmaking skills and even fewer are able to successfully grade patterns. This indicates additional attention needs to be given to current curriculums to address this deficit. Proficiently fitting prototype garments had the highest mean score of any future skill required of technical designers in the industry. For them, the ability to properly fit a garment was also cited as a frequently encountered skill deficit in entrylevel designers.

Ashdown [11] maintains that student involvement in technical apparel design has shifted over the last 30 years, as changes have occurred in the students, the apparel industry, and educational institutions. Effective teaching of the modern student of technical apparel design engages students in such a way that the topic is perceived as providing useful skills, as having value for their own goals and passions, and as an exciting endeavour requiring creativity. Topics encompassed in technical apparel design include traditional patternmaking, computer-aided patternmaking, grading, an understanding of apparel fit and proportion and how to achieve it, product development processes, industrial sewing methods and manufacturing processes. Patternmaking often focuses on custom fit only, using a couture model that is seen as the key to maintaining quality.

Most fashion universities work on static dress forms for students to develop pattern cutting and draping, evolving to using a model for fashion shows. The static dress form neither moves nor complains that clothing is too tight or restrictive in movement. These dress forms are available in a multitude of sizes, yet their form is flat and smooth, not the same as women who have curves and bumps, especially in larger body mass women. Barnes [12] highlighted body mass of women relative to their Body Mass Index (BMI) showing how different women gain weight in different places. The study explored all options for measurement of the human body using a 3D scan and as a result theorized that measurement of volume, as opposed to linear measurement, as used for apparel manufacture and design, was probably the best option to provide a measure of weight distribution. The study on body shape and weight distribution created the Body Volume Index (BVI) currently used in health care industry. However, the findings, as shown below in Fig. 1, highlight women's different body shapes; and as stated above, the apparel manufacturing industry use linear measurements and do not consider the body volumes when creating apparel.
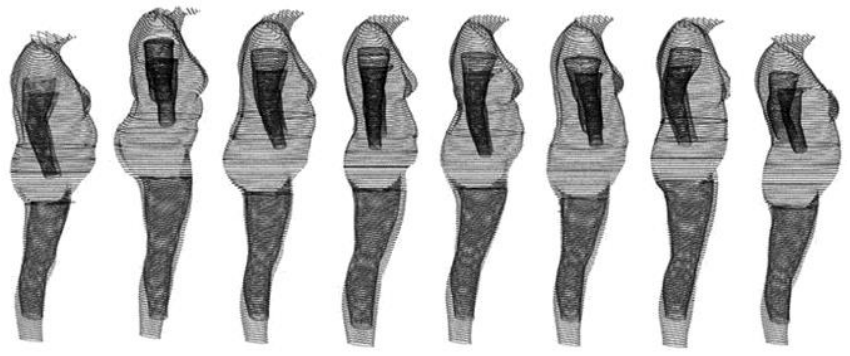

Fig. 1. Eight women with a BMI of 30, highlighting different body shapes. Eight women with a BMI of 30, highlighting different body shapes. Barnes [12].

Ashdown [11] claims that one of the biggest challenges facing the professor of technical apparel design skills is in engaging the student's understanding of the importance of the needed skills, convincing them to invest the time needed to master skills that may be highly frustrating to practice at first, and to understand how these skills will help them achieve their ultimate goals. She believes that students want to connect, to cooperate, to share control and to make decisions, to create with their own tools, to discover and follow their own passions, to be respected, to be trusted, and to have their opinions valued.

Creating made to measure pattern cutting and construction technical courses enables learners to experience a higher level of pattern construction, in using their own body measurements, and not the static dress form, with the satisfaction and achievement of producing a garment which fits their actual body size. This enhanced learning could enhance the student's passion, which Ashdown [11] believes students need, to drive their need to know and learn appropriate skills. By gaining an understanding of body fit, on themselves, students will gain the knowledge and skills of made to measure construction and can repeat the process for any body shape or form. According to fashion designer Galliano 'The most exciting discoveries, the marvellous moments aren't with the sketchbook, but in the making' [13]. Understanding fit and form of clothing from a student's perspective will give them lifelong skills for the fashion industry. As previously quoted by Mintel [3] over $60 \%$ of online goods are returned. The fashion industry is looking for a solution to the fit of clothing, yet as stated by Ashdown [11] student involvement in technical apparel design has shifted over the last 30 years and yet universities are still delivering curriculum developed decades ago, in the same format of using the dress form to live fitting model for fashion shows, as shown by Ashdown. Unless educators develop viable new solutions to the fit of clothing, the new generation of fashion designers will create sizing charts based on the same methodologies as currently in use. Bougourd [14] study shows that most clothing companies prefer 'ready to use data' such as body size charts, as no comprehensive evaluation of size charts developed from anthropometric body measurements are available. Disconnects between anthropometric measures and size charts also contribute to discrepancies between the garments and the consumers that they are intended to fit, maintains Schofield [8]. It is not advanced $3 \mathrm{D}$ body scanning technology that is required, it is developing an understanding of pattern theory for figure shapes.

Hodges [9] states that global forces have shaped the fashion industry into a complex and far-reaching phenomenon. An increasingly expanding global economy and competition from developing nations require that companies conduct business and maintain market share on an international platform [15]. As a result, the need for a new type of professional has emerged; one who is capable of working within this highly dynamic, global environment [16]. Part of this new professional is one that understands the fit of clothing for a diverse global market, and has the skills and knowledge to know how to adapt patterns for different figure shapes to cater for the local market.

In the doctorate research study by Tanya Dove thousand two hundred and sixty-one subjects body scan measurements were made available from Manchester Metropolitan data bank for the quantitative data analysis. Continuous data analysis calculated frequency distributions, ranges, mean, median and standard deviations. The principle component analysis (PCA) was employed to create the size range, where 
clusters of hip girths were grouped, creating the horizontal component of the PCA. Three defined figure shapes were identified from the study, the curvy figure has a larger bottom to waist ratio, with the straight figure a thicker waistline to hip ratio. Outer lying figure shapes are extremes of curvy and straight, with a larger bottom or a rectangular figure shape.

Alexander [17] determines that consumers' bodies change in a variety of ways that are not uniform across the different body areas. As women gain weight, the widest part of the body may not always be around the hips as it is often assumed A USA size 14 corresponds loosely with a UK size 18 . This is still within core body measurements used by mass production, and yet as Alexander's research showed, women gain weight in different areas of their body, and the current industry practice of increasing size ranges to reflect the body proportions of the fit model are outdated and do not reflect figure shapes of the consumers.

\section{MOOC COURSES IN MAdE TO MEASURE GARMENT} TECHNOLOGY

To facilitate better learning and training activities, the uses of online resources have to be blended successfully with education, [18]. One of these areas is known as e-learning, which offers the online delivery of information, communication, education and training. Liaw [19] puts forth three issues that have to be considered for designing effective e-learning environments, learner characteristics, instructional structure, and interaction. Learners come with different characteristics, so their attitudes; motivations, beliefs, and their confidence have to be identified. Sun [20] maintains that for e-learning to be successful, instructors need to remain as close as possible to the online environment to be able to design the e-learning environment to help students engage with the tools and the knowledge they are teaching. Yuan [21] states the reason why people take on MOOCs is due to flexibility. Chang [22] states that future directions with elearning models are to develop the combined efforts from interactive learning and technology-based learning, which can be managed and delivered more effectively. This would ensure that the learners' progress can be checked and monitored, so that learners can understand their weaknesses and areas that need to pay more attention.

A Professional Certificate in Fashion Design and Creation was launched in September 2019, by Hong Kong Polytechnic University, on the edX.org platform. The certificate comprises of two fashion MOOC courses, Designing and Creating Skirts and Designing and Creating Trousers. These are the only comprehensive online fashion design courses of their kind, teaching a 'made-to-measure' construction method, which is a superior form of garment construction method, than other methods used. This 'madeto-measure' technical innovation sets this course apart from other university patternmaking courses. The advantages of 'made-to-measure' include unlimited possibility to customize the garments, flexible adaptation according to all body types, better fitting than the ready-to-wear garments, and easier execution of 'zero waste' design concept.

Both MOOC courses were developed with the same learning strategy to enable global learners to complete one course, and begin the second with a sense of familiarity in the structure and delivery. The learning curve of the courses followed a five-unit structure: -

1) Collate anthropometric body measurements by manual means and using a body scanning mobile application

2) Develop a made to measure garment block

3) Gain an understanding of garment components and details

4) Develop an inspiration for design and create a range of six garments

5) Create one finished garment, made to measure with specification sheet on pattern and construction information

Each of the units had a mixture of video presentations, static presentations, interactive exercises and a range of quizzes and knowledge checking exercises. Fit solutions were posted online, with a question and answer structure over possible solutions to fit concerns. Forums were set up to encourage interaction between global learners, which were monitored by the MOOC team. Discussions over the fit of clothing and what inspires the learners for design, where staff and learners all responded to different feeds. Three assessments were developed for the courses, two selfassessment and the final project as a peer assessment. The MOOC platforms were set up to be engaging, interactive and informative, where learners had a high achievement rate as they were doing something for themselves. This method of learning, where it becomes personal, encouraged students to be perfectionists. They wanted to achieve the perfect fit for themselves, and subsequently learnt the art of made to measure.

Designing and Creating Skirts was launched on $9^{\text {th }}$ September 2019 and received over 2000 global learners. Within the global learner cohort there were 88 students from Hong Kong Polytechnic completing the course. They were first time pattern and sewing students, with no, or limited prior experience in garment construction. The usual delivery mode was presentation, demonstration, exercise. Where students learnt 'what and how to do' in a presentation, followed by a live demonstration, before completing an exercise. This method has fundamental flaws because not all students retain the information to be able to successfully complete the exercise, and consequently get stuck and feel frustrated. By having video presentations of the demonstrations live online enabled learners to watch the video via their mobile phone to complete the exercise. This not only relived the instructor of giving additional 1-1 assistance in the learning curve, it gave the students a sense of satisfaction at the ability to complete the task in hand. With all the online MOOC resources students were encouraged to watch videos and presentations before class, which flipped the classroom into an interactive pro-active environment. Students were able to achieve high results, not only in the learning curve but also their level of creativity. The understanding of 'how' to create garments, opened up their creativity levels in designing more complex garments for their final assessment. As students were completing the course in a made to measure capacity, their attention to detail and desire to achieve high results was not just for the final grade, but also to create a garment they were confident to model and wear.

The pre-course survey statistics completed by 322 respondents showed that $39 \%$ had no prior knowledge of designing clothes, with $83 \%$ wanting to complete the course to design and make their own garments. The 'best fit' forum allowed learners to discuss their own purchase problems with mass produced clothing, where a high number of respondents 
reported fit issues, where the waist fitted the hip did not, garment length problems, and specific styles which do not suit or fit their figure shape. A high proportion of posts in the forum showed women with fit problems in high street garments, but with no solution on how to improve the fit, some learner comments are shown below.

- In my experience with the trousers and skirts I buy in regular stores; in most cases the waist is too tight.

- I have always had problems with the fit of skirts and trousers. because I am 5' foot even, everything is too big and too long for my body type.

- I have issues with store bought dress pants fitting me correctly.

- Hi everyone I really don't have trousers or skirts that fit.

- I always have the same issues with skirts and trousers... if the fit my hip then the waist is too big

- The pants on the other hand I have an issue with. They don't fit as well in my waist

- I'm not a large person but it seems the thigh area is a particularly problematic area when buying both skirts and trousers.

- Hi, I always find that most skirts fit uncomfortably on my waist, and then during the day they ride up and twist around.

- I always have trouble finding pants, they never seem to fit anywhere, and I assume I have a pretty normal body type.

- There's a $12 \mathrm{~cm}$ difference between my waist and high hip which makes fitting skits and dresses difficult.

- $\quad$ Trousers that fit my hips are usually loose in the waist. When I find close-fitting trousers, they're usually too short in the crutch.

As stated previously, Mintel [3] statistic of $60 \%$ of goods being returned could be contributed by the fit of clothing. Online learners were also confused as to what shops to purchase clothes in, not knowing what size would fit them, or how the individual garments would look and fit their body shape.

The post course skirts survey received 84 respondents, where $98 \%$ said the video's helped them learn. 93\% stated the assessment briefs were clear to follow, with $90 \%$ of respondent's expectations for the course being met. A high proportion of learners wish to learn more, 92\%; with $97 \%$ having the confidence to alter garments purchased from the high street. The negative feedback received was the timing of the course. As this was the first run it was an instructor led 6 weeks run. As stated by Yuan [21], the reason why people take on MOOCs is due to flexibility. In February 2020 the course will re-launch and be self-paced, where learners are able to take their time to complete the course, without deadline pressures. Designing and Creating Trousers course launched on $11^{\text {th }}$ November 2019, instructor paced for 6 weeks duration. Initial pre-survey results obtained by 53 respondents show only $38 \%$ are happy with the fit of trousers. Only $26 \%$ are happy with the bottom fit of trousers, with $36 \%$ being happy with the length of trousers. $52 \%$ of respondents are completing the MOOC course because clothes do not fit their body shape correctly, with $92 \%$ wanting to make clothes for themselves and others upon completion of the course.

The Professional Certificate in Fashion Design and Creation has reached a global audience, with the Skirts MOOC attracting learners from 142 countries, and Trousers
MOOC reaching 137 countries. 15\% were from the USA, 7\% in Hong Kong and up to $6 \%$ of learners from India. There was a significantly higher enrolment of women, at $77.3 \%$ in skirts, and $68.4 \%$ in trousers.

The age of learners, shown in Fig. 2 below, shows the highest age category being $26-40$ years, with $46 \%$ of enrolment. These statistics show the global audience wanting to learn is not as young as college age (under 25), with the median learner age being 29 in both courses. The learners are educated, with $48 \%$ holding a college degree and $23 \%$ an advanced degree.

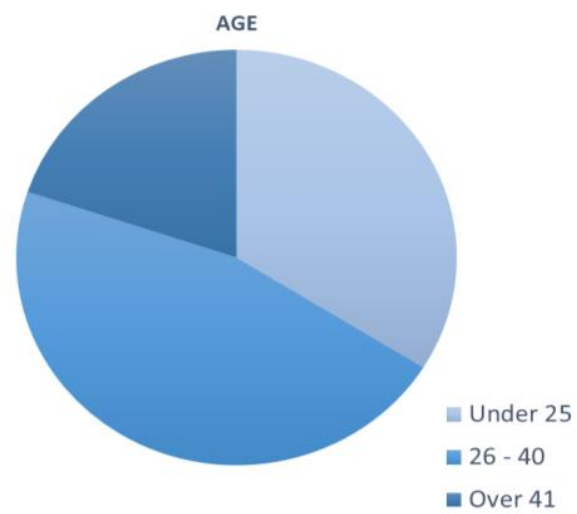

Fig. 2. Age statistics of MOOC learners. Age statistics of MOOC learners. www.edx.org.

\section{CONCLUSION FINDINGS}

The Professional Certificate in Fashion Design and Creation MOOC courses have comprehensive teaching materials in an interactive online environment, where learners are encouraged to discuss fit issues in the forums, and exchange designs and opinions on design and creation. The quizzes enabled learners to recap their knowledge in a fun and less formal manner, with a crossword quiz, a quickfire quiz and a drag and drop quiz exercise. As stated by Ashdown [11], one of the biggest challenges facing the professor of technical apparel design skills is in engaging the student's understanding of the importance of the needed skills. This was achieved by developing made to measure courses. When a learner is doing something specific for themselves the learning is enhanced as it becomes personal. This method of educating, where learners engage through activities, rather than teacher led discussions and demonstrations, enables the learner to develop the skills at their own pace, gaining a higher level of comprehension. Using this course in a blended capacity taught the students a higher level of pattern making and construction than would have been achievable within the semester, with the satisfaction level of the students was high due to making something for themselves. All students received high online grades for their completed works, with $94 \%$ of post course survey respondents saying they would recommend the course to a friend.

The 88 Hong Kong Polytechnic students were men and women, of all shapes and sizes. The online instructional videos and presentations are all developed with a made to measure approach, to create individual garment blocks made from anthropometric measurements. The fashion industry has fundamental problems with the fit of clothing. Highlighted by Ashdown pattern making often focuses on custom fit only, using a couture model that is seen as the key to maintaining 
quality. This method of pattern cutting and construction is not providing students will the knowledge and skills of the fit of clothing. The two MOOC courses, delivered by made to measure garment blocks are teaching learners not only how to make clothes, but fit assessment and body shape variations. They are guiding 1000's of global learners on how clothes can, and should, fit us, providing the skills to conduct alterations, knowing how to achieve the perfect fit for an individual body shape. These fundamental skills are what the fashion industry needs to help improve the fit of clothing from a global perspective.

\section{CONFLICT OF INTEREST}

The author declares no conflict of interest.

\section{REFERENCES}

[1] L. O'Connell. (2020). Total retail sales worldwide from 2018 to 2022. [Online]. https://www.statista.com/statistics/443522/global-retail-sales

[2] Apparel. [Online]. Available:

Available:

3] Mintel. (2017). [Online]. Available: www.mintel.com/presscentre/fashion/uk-online-sales-of-clothing-fashion-accessories-andfootwear-frowth-by-17-in-2017

[4] S. Gill, "A review of research and innovation in garment sizing, prototyping and fitting," Textile Progress, vol. 47, no. 1, pp. 1-85, 2015.

[5] E. A. Gribbin, "Body shape and its influence on apparel size and consumer choices," in Designing Apparel for Consumers, M. E. Faust, Ed. Cambridge: Woodhead Publishing Limited, 2014, pp. 3-16.

[6] J. P. Bougourd, L. Dekker, P. G. Ross, and J. P. Ward, “A comparison of women's sizing by $3 \mathrm{~d}$ electronic scanning and traditional anthropometry," The Journal of The Textile Institute, vol. 91, no. 2, pp. 163-173, 2000.

[7] D. E. Kim, K. LaBat, E. Bye, M. Sohn, and K. Ryan, "A study of scan garment accuracy and reliability," The Journal of The Textile Institute, vol. 8, pp. 853-861, 2015.

[8] N. A. Schofield, "Pattern grading," in Sizing in Clothing, S. P. Ashdown, Ed. Cambridge, Woodhead Publishing Limited, 2007.

[9] N. Hodges and E Karpova, "Making a major decision: An exploration of why students enroll in fashion programmes," International Journal of Fashion Design, Technology and Education, vol. 2, nos. 2-3, pp. 47-57, July 2009.

[10] L. D. Romeo and Y-A. Lee, "Creative and technical design skills: Are college apparel curriculums meeting industry needs?" International Journal of Fashion Design, Technology and Education, vol. 6, no. 3, pp. 132-140, 2013
[11] S. P. Ashdown, "Not craft, not couture, not "home sewing': Teaching creative patternmaking to the iPod generation," International Journal of Fashion Design, Technology and Education, vol. 6, no. 2, pp. 112120, 2013.

[12] R. Barnes, "Body shape and weight distribution: The body volume index (BVI) And the body mass index (BMI)," in Designing Apparel for Consumers, M. E. Faust, Ed. Cambridge: Woodhead Publishing Limited, 2014, pp. 58-77.

[13] C. McDowell, Galliano, London: Weidenfeld \& Nicolson, 1997.

[14] J. Bourgourd and P. Trevlean, "National side and shape surveys for apparel design," in Anthropometry, Apparel Sizing and Design, D. Gupta, Ed. Woodhead Publishing, 2014.

[15] I. Taplin, "Continuity and change in the US apparel industry: A statistical profile," Journal of Fashion Marketing and Management, vol. 3, pp. 360-368, 1999.

[16] N. N. Hodges and E. Karpova, "Employment in the U.S. textile and apparel industries: A comparative analysis of regional vs. national trends," Journal of Fashion Marketing and Management, vol. 10, pp. 209-226, 2006.

[17] M. Alexander, G. R. Pisut, and A. Ivanescu, "Investigating women's plus size body measurements and hip shape variation based on Size USA data," International Journal of Fashion Design, Technology and Education, vol. 5, issue 1, pp. 3-12, 2012.

[18] M, Sloman, The e-Learning Revolution from Propositions to Action, 1st ed. Charted Institute of Personnel and Development, 2001.

[19] S. S. Liaw, "Considerations for developing constructivist web-based learning," International Journal of Instructional Media, vol. 31, no. 3, p. 309, 2004.

[20] P. C. Sun, R. J. Tsai, G. Finger, Y. Y. Chen, and D. Yeh, "What drives a successful e-Learning? An empirical investigation of the critical factors influencing learner satisfaction," Computers and Education, vol. 50, no. 4, pp. 1183-1202, 2008.

[21] L. Yuan and S. Powell, "MOOCs and open education: Implications for higher education, technical report," JISC Cetis, 2013.

[22] V. Chang, "Review and discussion: E-learning for academia and industry," International Journal of Information Management, vol. 36, pp. 476-485, 2016.

Copyright (C) 2020 by the authors. This is an open access article distributed under the Creative Commons Attribution License which permits unrestricted use, distribution, and reproduction in any medium, provided the original work is properly cited (CC BY 4.0).

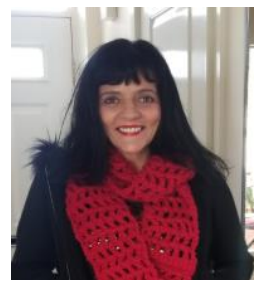

Tanya Dove is a lecturer at Hong Kong Polytechnic University, within the Institute of Textiles and Clothing. She is also a $\mathrm{PhD}$ part time student with Manchester Metropolitan University in the UK. Her research 'Optimised Sizing Systems', has developed a pattern cutting framework to improve the fit of women's clothing. She teaches across design and technology, where she uses the made to measure MOOC courses to facilitate teaching and learning. 